Research article

\title{
Highly efficient lead extraction from aqueous solutions using inorganic polymer foams derived from biomass fly ash and metakaolin
}

\author{
Rui M. Novais *, João Carvalheiras, Maria P. Seabra, Robert C. Pullar, João A. Labrincha \\ Department of Materials and Ceramic Engineering / CICECO-Aveiro Institute of Materials, University of Aveiro, Campus Universitário de Santiago, 3810-193, Aveiro, \\ Portugal
}

\section{A R T I C L E I N F O}

\section{Keywords:}

Alkali-activated material

Adsorption

Waste

Lead

Foam

\begin{abstract}
A B S T R A C T
This work reports a simple and safe, but powerful, route to depollute lead-containing aqueous solutions. Inorganic polymer foams (cm-size) were used as bulk-type adsorbents. The influence of the specimens' porosity and activator molarity on the foams' physical properties and on their lead extraction ability was studied. Then, the best performing samples were deeply evaluated as lead adsorbents by studying the impact of $\mathrm{pH}$, lead concentration, contact time, ionic strength and solution volume. Lead sorption kinetics is strongly affected by the pollutant concentration, $\mathrm{pH}$ and the solution ionic strength. Under the most favourable conditions the foams showed an impressive removal capacity $\left(105.9 \mathrm{mg} / \mathrm{g}\right.$ at $\mathrm{pH} 5,23{ }^{\circ} \mathrm{C}, \mathrm{C}_{0}=800 \mathrm{ppm}$, deionised water), surpassing all other reported values on the use of bulk-type inorganic polymers. The foams' lead uptake is 2.3 times higher than the previous best performing bulk-type specimens (mm-size spheres), and sorption is 12.5-15 times faster. The foams can be easily regenerated using mild acidic conditions, and then reused as adsorbent, suggesting that the main adsorption mechanism is ion exchange.
\end{abstract}

\section{Introduction}

The availability of fresh water has long been recognised as a global systemic risk (Mekonnen and Hoekstra, 2016), which is expected to reach critical values in the near future. Industrial wastewaters could be a non-conventional water source, provided that toxic elements frequently found in effluents coming from various industries are removed, ideally using low-cost, environmentally benign and very effective methods. Amidst the numerous heavy metals found in industrial effluents, lead is one of the most toxic (Siyal et al., 2018), known to have severe effect on human health, and therefore we have use it as model heavy metal.

The elimination of metal ions from wastewaters using different techniques (Alharbi et al., 2020; Gopinath et al., 2020) and materials (Hu et al., 2020; Pang et al., 2019) has been deeply investigated. Among the various existing techniques, adsorption stands out as the most widely used procedure due to its simplicity and efficiency. Activated carbon is the benchmark adsorbent, owing to its very high specific surface area (SSA) endowing excellent extraction ability. Nevertheless, the production of these materials has very high associated costs hindering their wider use (Fu and Wang, 2011). Alternative low-cost materials are in great demand. Inorganic polymers (IPs) are promising candidates because of the possibility of being synthesised with relatively low energy input and using industrial wastes or by-products as precursors. Besides the projected economic and environmental advantages over activated carbons, these materials are intrinsically nano- (Kriven et al., 2003) and micro-porous (Bai and Colombo, 2018) and have a negatively charged framework balanced by cations such as $\mathrm{Na}^{+}$or $\mathrm{K}^{+}$, that can be substituted by other cations via ion exchange to enable their use as adsorbent (Novais et al., 2019b). Despite being a fairly recent research topic, the existing literature demonstrates the huge potential of this technology for wastewater treatment (Novais et al., 2020; Siyal et al., 2018). Nevertheless, in most of the studies $\mu \mathrm{m}$-sized IP powders are used to depollute wastewaters. This strategy ensures a high heavy metal uptake but requires a post-separation step to recover the adsorbent, increasing the complexity and cost of wastewater treatment. Recently, a safer and simpler strategy was proposed: the use of IP foams (mm or cm-size) (Ge et al., 2015; Novais et al., 2016b) that can be used without the need for support materials. Despite being a very promising route, the available literature is still limited. Up to now, there are only four studies where bulk-type IP adsorbents were used to extract lead from synthetic waters. One of these works addresses the use of cylindrical discs $(22 \mathrm{~mm}$ diameter and $3 \mathrm{~mm}$ thickness), the maximum observed uptake being 6.3

\footnotetext{
* Corresponding author.

E-mail address: ruimnovais@ua.pt (R.M. Novais).
} 
$\mathrm{mg} / \mathrm{g}$ (24 h sorption) (Novais et al., 2016b). Faster and higher lead uptake ( $4 \mathrm{~h}, 16.5 \mathrm{mg} / \mathrm{g}$ ) was reported when using IP granules $(4<\mathrm{d}<$ $11.2 \mathrm{~mm}$ ) (Bumanis et al., 2019), while the use of IP supported zeolites resulted in a slightly lower uptake $(15.8 \mathrm{mg} / \mathrm{g}$ ) than in (Bumanis et al., 2019) when using similar sorption time (6 h), but much higher values were seen when extending the sorption to $120 \mathrm{~h}(37.9 \mathrm{mg} / \mathrm{g}$ ) (Khalid et al., 2018). The highest lead uptake ever reported for bulk-type ( $\mathrm{mm}$ or $\mathrm{cm}$ size; not powders) adsorbents was achieved when using IP spheres $(2<\mathrm{d}<4 \mathrm{~mm})$. The spheres showed an impressive lead uptake of 45.6 $\mathrm{mg} / \mathrm{g}$, but again using very long sorption times $(60 \mathrm{~h})$ (Tang et al., 2015). These studies suggest that the use of bulk-type IPs as lead adsorbent is feasible. However, additional studies are required to fully demonstrate the viability of this innovative strategy in comparison with the conventional approach (the use of powdered adsorbents), and to provide insights into influencing factors on lead adsorption by $\mathrm{cm}$-size IP adsorbents that have not been considered up to now (e.g. activator molarity; initial lead concentration; ionic strength).

In wastewater treatment systems, $\mathrm{pH}$ plays a critical role on the heavy metals extraction (Alwan, 2012, 2008) and should be strictly controlled and adjusted to preserve high efficiency levels. Lead adsorption by IPs is known to be strongly affected by the solutions $\mathrm{pH}$. At low $\mathrm{pH}$ values $(<2)$ the adsorption is much lower than that seen when the $\mathrm{pH}$ is between 4 and 5 , and this feature has been associated with the competition between the $\mathrm{H}^{+}$and the $\mathrm{Pb}^{2+}$ ions for the adsorption sites (Al-Zboon et al., 2011; Cheng et al., 2012).

In the present work, cm-size waste-based IP foams were evaluated as a lead adsorbent material. The foams were intentionally prepared using different activator concentrations and foaming agent contents, to evaluate the influence of the $\mathrm{NaOH}$ molarity and specimen porosity on the lead removal ability of the foams. The adsorption of $\mathrm{Pb}^{2+}$ was studied as a function of sorption time, $\mathrm{pH}$, pollutants initial concentration, adsorbent dosage and the solution' ionic strength. This study provides additional insights on the use of $\mathrm{cm}$-size IP foams as lead adsorbent material aiming to decrease the existing knowledge gap regarding these bulktype environmentally friendly and low-cost materials.

\section{Experimental conditions}

\subsection{Materials}

Two solid precursors were used to synthesise the IPs: biomass fly ash, deriving from the burning of residual biomass coming from forestry operations, and metakaolin (Argical ${ }^{\mathrm{TM}}$ M1200S, Univar $\left.{ }^{\circledR}\right)$. The precursors were chemically activated using a mixture of sodium silicate $\left(\mathrm{SiO}_{2} / \mathrm{Na}_{2} \mathrm{O}=3.1,62.1 \mathrm{wt} \% \mathrm{H}_{2} \mathrm{O}\right.$, Quimialmel, Portugal) and sodium hydroxide (ACS reagent, 98\%; AkzoNobel) solutions (8 or $10 \mathrm{M}$, depending on the composition).

To promote in-situ foaming of the slurry, a commercial aluminium powder was used (Expandit BE 1101, Grimm Metallpulver GmbH) coupled with an anionic surfactant (Hotaspur OSB, Clariant) to stabilise the liquid-gas interface.

The $\mathrm{Pb}^{2+}$ solutions were prepared by dissolving lead (II) nitrate (ASC reagent; 99\%, Merck) in deionised water.

\subsection{Mixture design and foams preparation}

The mixture design was selected following previous work (Novais et al., 2019a). The foams synthesis protocol is described in the Supplementary Material. Four different compositions were prepared to evaluate the influence of the $\mathrm{NaOH}(8$ and $10 \mathrm{M})$ and foaming agent amount ( 0.05 and $0.10 \mathrm{wt} \%)$ on the specimens' porosity and, therefore, in their heavy metal removal capacity.

Before the adsorption tests, the foams were neutralised in $0.05 \mathrm{vol} \%$ $\mathrm{HNO}_{3}$ (Panreac 65\%, ISO) for $60 \mathrm{~min}$, and then washed with distilled water until the $\mathrm{pH}$ of the wash water was stable at $7.0 \pm 0.5$. This is because, IPs have unreacted alkalis in their framework which need to be extracted before their use as adsorbents (Novais et al., 2016b) to avoid lead precipitation.

\subsection{Lead sorption tests}

Parallelepiped foams (10 mm width, $7 \mathrm{~mm}$ thickness and $27 \mathrm{~mm}$ length) were used to extract lead from wastewaters, testing the influence of the pollutant concentration, $\mathrm{pH}$, contact time, solution volume and ionic strength, and the specimens' porosity. Two different assays were performed: i) preliminary performance assessment: four different compo-

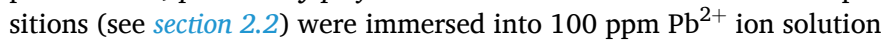
$(100 \mathrm{~mL})$ and magnetically stirred for a predetermined period $(1,4$ and $6 \mathrm{~h})$ at $360 \mathrm{rpm}$. The most cost-effective specimen was selected for the second stage; ii) in-depth performance assessment: the best performing foam (8 M_0.10Al) was evaluated under various pollutant concentrations (100-800 ppm), contact times (1-4 h), pH (2-5), solution volumes (100-250 mL) and ionic strengths $(0,0.01$ and $0.1 \mathrm{mM} \mathrm{NaCl})$. Adsorption was performed at $23{ }^{\circ} \mathrm{C}$.

The concentration of $\mathrm{Pb}^{2+}$ was determined by inductively coupled plasma - optical emission spectroscopy (ICP-OES, Horiba Jobin Yvon, Activa M), whose detection limit is $0.02 \mathrm{ppm}$ (for lead).

The lead removal efficiency (E) and uptake $\left(q_{e}\right)$ were determined using equation Eq. (A1) and Eq. (A2), respectively (appendix).

\subsection{Regeneration of the foams}

To evaluate the possibility of reusing the adsorbent, desorption tests were performed on samples obtained in the lead adsorption tests. The adsorbents were added to $100 \mathrm{~mL}$ of $\mathrm{HNO}_{3}(0.01 \mathrm{vol} \%)$ and shaken at $360 \mathrm{rpm}$ for a predetermined period $(1$ or $2 \mathrm{~h})$ at $23^{\circ} \mathrm{C}$. Then, the foams were washed with water and dried overnight at $80^{\circ} \mathrm{C}$. Afterwards, the samples reusability was evaluated using a $100 \mathrm{ppm} \mathrm{Pb}^{2+}$ solution (100 $\mathrm{mL}, \mathrm{pH} 5$, contact time $4 \mathrm{~h}$ ).

\subsection{Materials characterisation}

The foams microstructure was evaluated using scanning electron microscopy (SEM-Hitachi SU70) equipped with energy dispersion spectroscopy (Bruker EDS).

The bulk density of the samples was determined by measuring their weight and volume. The true density of un-foamed samples (prepared exclusively for this test) was assessed by a helium pycnometer (Multipycnometer, Quantachrome): $2.37 \mathrm{~g} / \mathrm{cm}^{3}$ and $2.30 \mathrm{~g} / \mathrm{cm}^{3}$, respectively, for the specimens activated with 8 and $10 \mathrm{M} \mathrm{NaOH}$. Then, the total porosity of the foams (before and after alkalis leaching) was determined (Novais et al., 2016a).

The water absorption of the samples after alkalis leaching was evaluated by immersing them in distilled water for $24 \mathrm{~h}$, or until the specimens' mass was stable for at least $60 \mathrm{~min}$. Three samples per composition were measured.

The zeta-potential of sample $\boldsymbol{8} \boldsymbol{M}_{-} \mathbf{0 . 1 0 A l}$, the most cost-effective specimen (section 3.2.1), was determined using a Zetasizer Nano ZS (Malvern) using $\mathrm{HCl}$ or $\mathrm{NaOH}$ to control de $\mathrm{pH}$. The measurements were done at $23^{\circ} \mathrm{C}$ using deionised water and different concentration of $\mathrm{NaCl}$ $(0,0.01$ and $0.1 \mathrm{mM})$ to evaluate the influence of the ionic strength.

X-ray micro-computed tomography was used to evaluate the foams' porous structure using a Bruker SkyScan12 Micro CT tomograph (set to $50 \mathrm{kV}$ and $200 \mu \mathrm{A}$ ), with a resolution of $8 \mu \mathrm{m}$. The tests were done using cubic foams of $\sim 1 \mathrm{~cm}^{3}$.

The SSA of the adsorbents (after alkalis leaching) was determined using the Brunauer-Emmett-Teller (BET) method by $\mathrm{N}_{2}$ adsorption using a 5-point BET method on a Micromeritics Gemini 2380 surface area analyser. Tests were performed using bulk specimens (not powders), which were first outgassed at $120^{\circ} \mathrm{C}$ for $12 \mathrm{~h}$.

The presence of crystalline phases in the samples (before and after acid treatment) was assessed by using X-ray powder diffraction (XRD, 
Rigaku Geigerflex D/mx-Series Instrument, $\mathrm{Cu}$ K $\alpha$ radiation, 10-80 2 , scan of $0.02^{\circ} 2 \theta$ per step and $10 \mathrm{~s} / \mathrm{step}$ ).

Fourier-transform infrared spectroscopy (FT-IR) measurements, in attenuated total reflectance (ATR) mode, of the adsorbent, before and after lead adsorption, were carried out on a PerkinElmer FT-IR System Spectrum BX spectrophotometer equipped with a single horizontal Golden Gate ATR cell. The measurements were performed at room temperature using $4 \mathrm{~cm}^{-1}$ in resolution, 256 scans in a range between 4000 and $350 \mathrm{~cm}^{-1}$.

\section{Results and discussion}

\subsection{Inorganic polymer foams characterisation}

Fig. S1 presents the bulk density and total porosity of the various specimens before and after the washing step. The extraction of alkalis from the samples led to a major drop in their bulk density, between 9 and $20 \%$ depending on the composition. The lowest bulk density was observed for the foam 10 M_o.10Al $\left(0.34 \mathrm{~g} / \mathrm{cm}^{3}\right)$. The decrease in the sample's density was found to be dependent of the mixture composition: samples prepared using higher $\mathrm{NaOH}$ molarity $(10 \mathrm{M})$ and foaming agent $(0.10 \mathrm{wt} \%)$ exhibited a larger variation than their lower molarity and porosity counterparts.

The specimens' weight loss (averaged from at least 10 samples), given in Table 1, further illustrates the differences observed for the various specimens, while the SEM micrographs presented in Fig. S2 show significant microstructural changes in the samples surface suggesting an increase in their porosity. This is particularly visible in the micrographs corresponding to the lowest porosity specimens, where an increase in the number of pores and the presence of cracks can be observed.

The SSA, water absorption and total porosity (measured from density and micro CT) of the various samples after the washing step are given in Table 1. For the lower molarity compositions, the SSA increases significantly with the increase in quantity of the foaming agent, from 27.0 to $45.1 \mathrm{~m}^{2} / \mathrm{g}$. Surprisingly, in the higher molarity foams only a minor increase in the SSA, from 44.3 to $46.3 \mathrm{~m}^{2} / \mathrm{g}$, is seen when increasing the foaming agent level from 0.05 to $0.10 \mathrm{wt} \%$. The unexpected high SSA value of $10 M_{-} \mathbf{0 . 0 5 A l}$ should be considered with caution. In fact, by comparing the other physical properties reported in Table 1 with those of specimen $\mathbf{8} \boldsymbol{M}_{-} \mathbf{0 . 0 5} \mathrm{Al}$, no significant differences are perceived.

To measure the impact of the washing step on the samples, the SSA of one of the foams (10 M_O.10Al) was also characterised before alkalis leaching. The SSA of the unwashed sample was $33.6 \mathrm{~m}^{2} / \mathrm{g}$, while after leaching the SSA reached $46.3 \mathrm{~m}^{2} / \mathrm{g}$, demonstrating that this process significantly increased the specimens' porosity, which will favour the lead extraction by the foams due to an increase in the number of active sites.

To further characterise the effect of the washing step on the specimens' chemical composition, EDS mapping was performed on all samples prior to and after washing. A representative example is given in Fig. S3, which shows the EDS maps and spectrum of the foam 8 M_0.05Al. The comparison between the EDS spectra and maps shows that sodium is almost depleted from the washed sample, a sixfold reduction from 13.4 to 2.4 at.\% being observed. The EDS maps also show that the acid treatment induces a slight reduction of calcium in the washed sample. Despite this, the XRD pattern of the specimen remains virtually unchanged (Fig. S4), suggesting that the extraction of alkaline soluble salts is the dominant event induced by washing.

The comparison between the total porosity values, measured by using the true and bulk density or the micro CT technique, shows that the values measured in the latter were roughly $14-19 \%$ lower. This is attributed to the limitation of the X-ray computed tomography, since with this technique pores below the pixel size $(8 \mu \mathrm{m})$ cannot be accounted for and, therefore, the given values are underestimated. The presence of many pores possessing diameters below $8 \mu \mathrm{m}$ can easily be discerned from the SEM micrographs shown in Fig. S5. Despite this, both techniques indicate that the $\mathrm{NaOH}$ molarity, at least within the values considered here (between 8 and $10 \mathrm{M}$ ), exerts an insignificant impact in the foam's total porosity, while the foaming agent plays the key role.

Although there were substantial microstructural changes in the specimens promoted by the washing step, it should be noticed that all samples preserved their integrity, as demonstrated by the digital photographs and the 3D images, shown in Fig. 1. The 3D images also show a greater pore connectivity in the specimens prepared using higher foaming agent amounts ( $0.10 \mathrm{wt} \% \mathrm{vs} 0.05 \mathrm{wt} \%)$, which is expected to strongly affect the lead removal ability of the foams.

\subsection{Lead adsorption tests}

\subsubsection{Preliminary performance assessment}

To evaluate the influence of the mixture composition on the IP foams' lead removal efficiency, samples having identical geometry (see

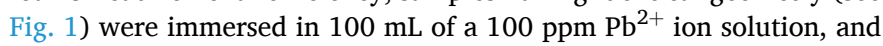
then stirred for up to $6 \mathrm{~h}$ at $\mathrm{pH}=5$. Fig. 2 presents the removal efficiency attained by the various samples as a function of contact time. In the 1st hour, the lead removal efficiency diverged significantly between the samples, ranging from 67.7 to $95.3 \%$. At this stage, the higher porosity specimens already showed much higher removal efficiency than their lower porosity counterparts, regardless of the $\mathrm{NaOH}$ molarity used in their synthesis. In fact, the lead uptake by these specimens doubles that reached by the lower porosity foams. For example, the $\mathrm{Pb}^{2+}$ uptake shown by 8 M_O.10Al reached $12.6 \mathrm{mg} / \mathrm{g}$, while being only $6.3 \mathrm{mg} / \mathrm{g}$ for $8 M_{-}$o.05Al. The highest removal efficiency during this period was observed for the composition 10 M_o.10Al (95.3\%), while the sample prepared with lower $\mathrm{NaOH}$ molarity had an efficiency $\sim 5 \%$ lower (90.2\%). Interestingly, the differences between the compositions were significantly attenuated for longer contact times. In fact, all samples showed removal efficiency above $96 \%$ after $4 \mathrm{~h}$, and 8 M_0.10Al reached an impressive $100 \%$, slightly higher than that seen with 10 M_0.10Al (99.4\%). Despite showing slightly lower removal efficiency, 10 M_O.10Al had a higher $\mathrm{Pb}^{2+}$ uptake $(16.6 \mathrm{mg} / \mathrm{g})$ vs $14.9 \mathrm{mg} / \mathrm{g}$ for 8 M_0.10Al, due to its lower bulk density $\left(0.34 \mathrm{~g} / \mathrm{cm}^{3}\right.$ vs $\left.0.38 \mathrm{~g} / \mathrm{cm}^{3}\right)$.

The use of even longer contact times $(6 \mathrm{~h})$ was only beneficial for the lower porosity foams, further enhancing their lead sorption up to $99 \%$, without affecting the removal efficiency of the higher porosity specimens. This means that the higher porosity samples reach their equilibrium after $4 \mathrm{~h}$, this being much smaller than the equilibrium times reported for other bulk-type IP adsorbents of $24 \mathrm{~h}$ (Novais et al., 2016b), $60 \mathrm{~h}$ (Tang et al., 2015) and $120 \mathrm{~h}$ (Khalid et al., 2018), with similar times being seen when using granules $(4-11.2 \mathrm{~mm}$ ) (Bumanis et al., 2019). Remarkably, the equilibrium time seen for the foams is also

Table 1

Physical properties of the inorganic polymer foams after alkalis leaching (washing step).

\begin{tabular}{|c|c|c|c|c|c|c|}
\hline Reference & $\begin{array}{l}\text { Specific surface area }\left(\mathrm{m}^{2} /\right. \\
\text { g) }\end{array}$ & $\begin{array}{l}\text { Total porosity (from density; } \\
\%)\end{array}$ & $\begin{array}{l}\text { Water absorption } \\
(\%)\end{array}$ & $\begin{array}{l}\text { Bulk density }(\mathrm{g} / \\
\left.\mathrm{cm}^{3}\right)\end{array}$ & Total porosity (micro CT, \%) & Weight loss (\%) \\
\hline $8 \mathrm{M} \_0.05 \mathrm{Al}$ & 27.0 & $75.4 \pm 0.8$ & $70 \pm 3$ & $0.58 \pm 0.02$ & 57.4 & $8.5 \pm 2.2$ \\
\hline $8 \mathrm{M} \_0.10 \mathrm{Al}$ & 45.1 & $84.0 \pm 0.4$ & $131 \pm 12$ & $0.38 \pm 0.01$ & 70.4 & $14.3 \pm 1.1$ \\
\hline $10 \mathrm{M} \_0.05 \mathrm{Al}$ & 44.3 & $75.4 \pm 2.0$ & $65 \pm 2$ & $0.57 \pm 0.05$ & 56.8 & $11.2 \pm 6.5$ \\
\hline $10 \mathrm{M} \_0.10 \mathrm{Al}$ & 46.3 & $85.3 \pm 0.4$ & $123 \pm 11$ & $0.34 \pm 0.01$ & 70.9 & $19.5 \pm 1.4$ \\
\hline
\end{tabular}




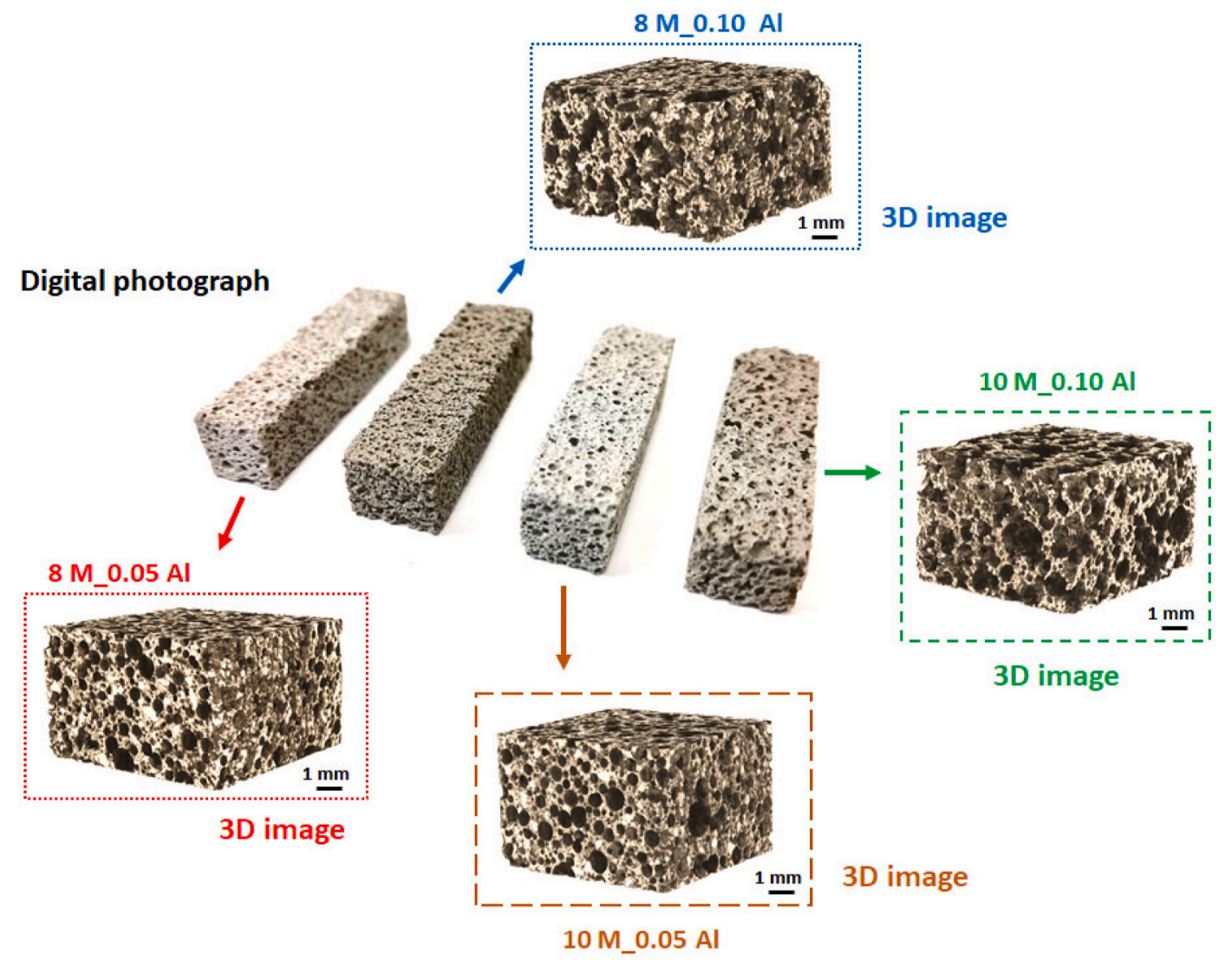

Fig. 1. Digital photographs and 3D images obtained by X-ray computed microtomography of the various inorganic polymer foams $\left(1.9 \pm 0.1 \mathrm{~cm}^{3}\right)$ used in the lead removal tests.

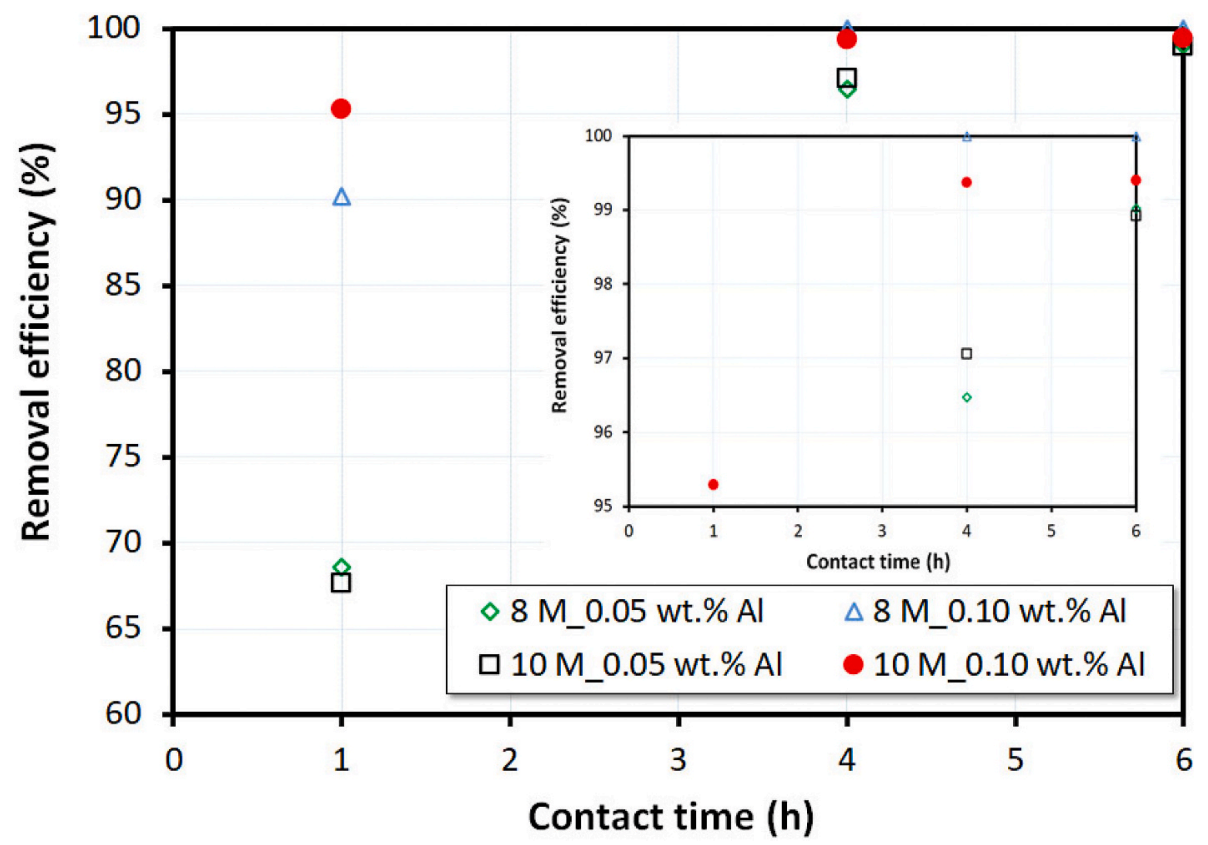

Fig. 2. Lead removal efficiency by the different inorganic polymer foams with sorption time ( $\mathrm{pH}=5$, volume: $\left.100 \mathrm{~mL},\left[\mathrm{~Pb}^{2+}\right]: 100 \mathrm{ppm}\right)$. The inset better illustrate the specimens' lead removal efficiency.

shorter than that reported for powdered IP adsorbents, which was $7 \mathrm{~h}$ (Andrejkovičová et al., 2016) or 24 h (Cheng et al., 2012), further demonstrating the interesting potential of these innovative adsorbents. The lead adsorption by the foams was further evaluated using EDS elemental analysis. Fig. 3 presents the EDS spectrum of $10 \mathbf{M} \mathbf{0} \mathbf{0 . 1 0 A l}$ before and after lead adsorption tests. Fig. $3 \mathrm{~b}$ clearly shows the presence of lead on the specimen's surface, absent before the test (see Fig. 3a). Additionally, the EDS maps given in Fig. 3c show a homogeneous 

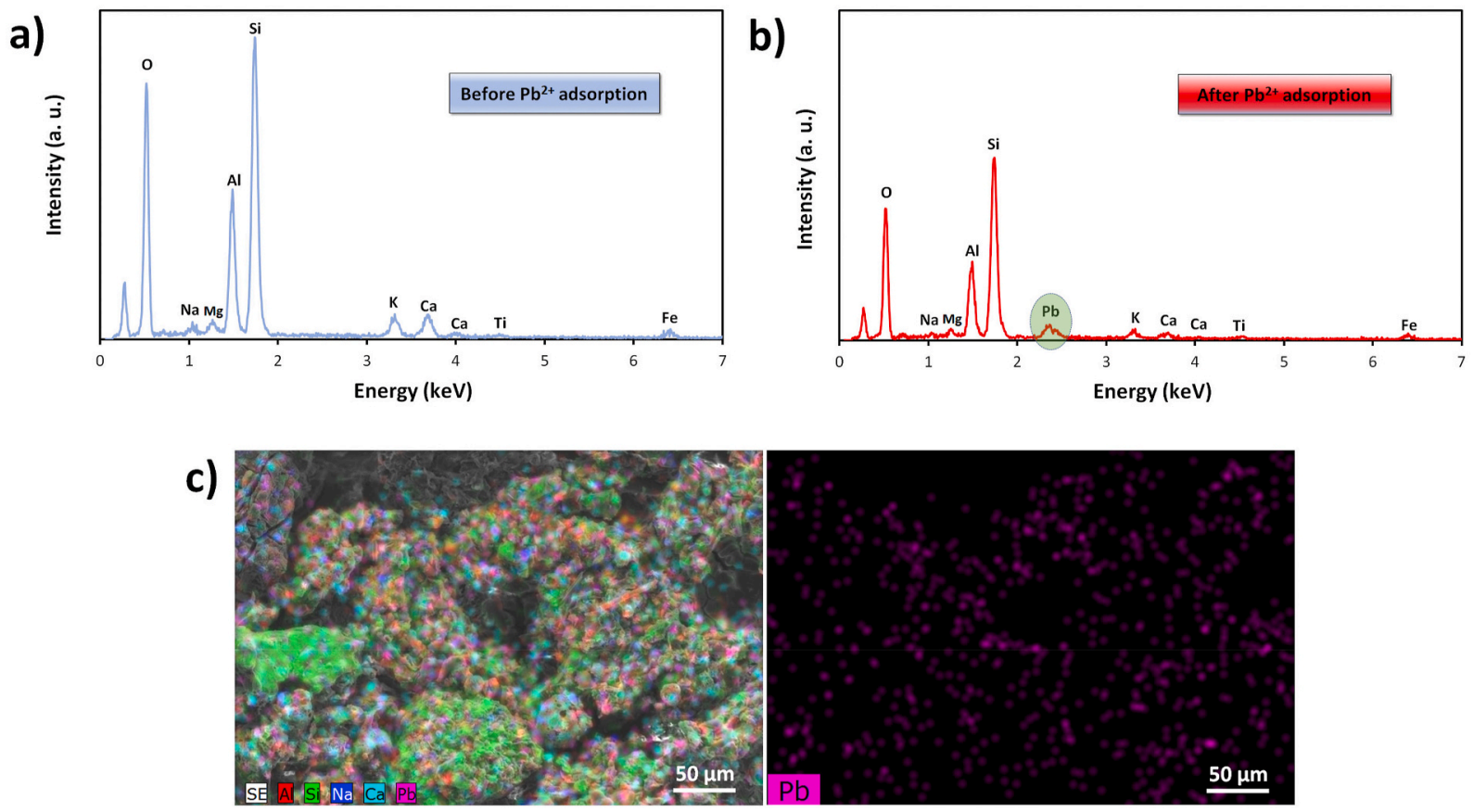

Fig. 3. EDS spectra of the specimen $10 \mathbf{M}_{-} 0.10 \mathrm{Al}$ before (a) and after (b) lead adsorption tests ( $\mathrm{pH}=5$, contact time: $6 \mathrm{~h}$, volume: $100 \mathrm{~mL}$, $\left[\mathrm{Pb}^{2+}\right]$ : $100 \mathrm{ppm}$ ), while Fig. $8 \mathrm{c}$ shows EDS maps of the specimen surface after adsorption illustrating the lead distribution.

distribution of lead on the foam's surface.

The results presented in Fig. 2 show that, regardless of the $\mathrm{NaOH}$ molarity, the higher porosity specimens (prepared with $0.10 \mathrm{wt} \% \mathrm{Al}$ ) present very large and rapid removal efficiency. Nevertheless, 8 M_0.10Al reached 100\% removal efficiency after $4 \mathrm{~h}$, slightly surpassing 10 M_0.10Al. Therefore, considering technical (higher removal efficiency), economic and environmental reasons (lower $\mathrm{NaOH}$ concentration in their synthesis), that composition was selected for the next stage.

\subsubsection{In-depth performance assessment}

3.2.2.1. Adsorbent zeta potential. Fig. 4 presents the zeta potential of 8 M_0.10Al as a function of $\mathrm{pH}$ and $\mathrm{NaCl}$ concentration. Within the studied $\mathrm{pH}$ interval (2-10), the surface of the adsorbent is negatively charged regardless of the $\mathrm{NaCl}$ content. The adsorbent's surface charge decreases as the $\mathrm{pH}$ increases, the highest charge density being observed at $\mathrm{pH}=9-10$. Previous studies have shown that lead adsorption by IPs is favoured at $\mathrm{pH}=5$ (Al-Zboon et al., 2011; Cheng et al., 2012). At this

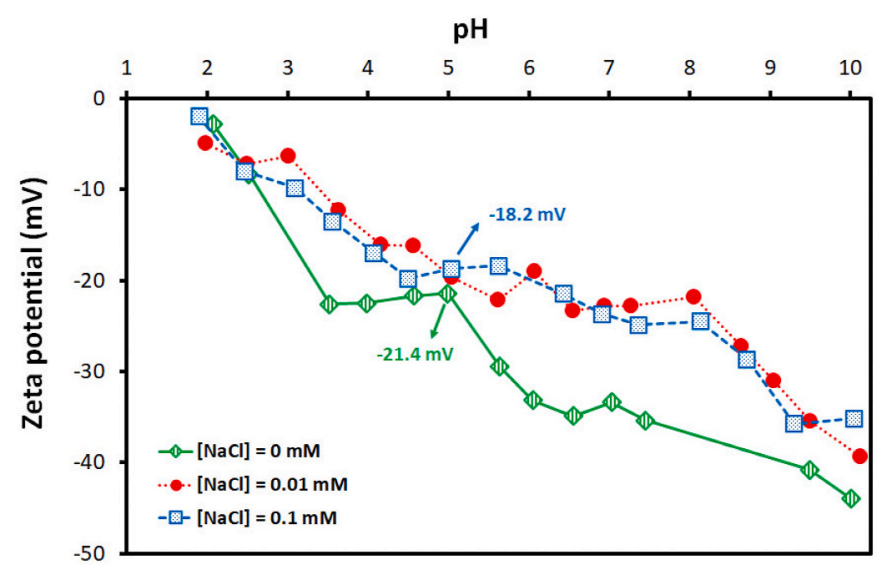

Fig. 4. Influence of $\mathrm{pH}$ and $\mathrm{NaCl}$ concentration on the zeta potential of the specimen prepared with $0.10 \mathrm{wt} \% \mathrm{Al}$ and using an $8 \mathrm{M} \mathrm{NaOH}$ solution (8M_0.10Al).
$\mathrm{pH}$, the adsorbent's surface charge within the studied $\mathrm{NaCl}$ concentrations is always smaller than that seen at higher pHs. However, and despite the lower surface charge, $\mathrm{pH}$ must be kept $\leq 5$ to prevent lead precipitation and ensure that lead is removed exclusively by adsorption. At $\mathrm{pH}=5$ the adsorbent is still expected to show good attraction to the cationic adsorbate $\left(\mathrm{Pb}^{2+}\right.$ ions) as indicated by the negative surface charge of $-21.4 \mathrm{mV}(0 \mathrm{mM} \mathrm{NaCl})$. Much lower attraction is foreseen at lower $\mathrm{pH}$ values, particularly below 4 , due to the significant increase in the surface charge of the foam.

Results also show that the ionic strength of the solution affects the adsorbents' surface charge properties, higher ionic strengths reducing the net surface charge. These results are associated with the competition between the $\mathrm{Na}^{+}$and the $\mathrm{H}^{+}$ions for the binding sites which is expected to hinder the adsorbent lead removal capacity (see section 3.2.2.4). At $\mathrm{pH} 5$, in the presence of $0.1 \mathrm{mM} \mathrm{NaCl}$ the adsorbent's surface charge is $-18.2 \mathrm{mV}$, this being $15 \%$ lower than the value seen in the absence of $\mathrm{NaCl}$. Similar findings have been reported for metakaolin-based IPs (López et al., 2014).

3.2.2.2. Influence of $\mathrm{Pb}^{2+}$ initial concentration. Fig. 5 presents the influence of the $\mathrm{Pb}^{2+}$ initial concentration on the uptake and removal efficiency of this heavy metal by the IP foam $8 \mathbf{M}_{-} \mathbf{0 . 1 0 A l}$. As mentioned in the previous section, the adsorbent can completely remove the $\mathrm{Pb}^{2+}$ ions when $C_{0}=100 \mathrm{ppm}$ within $4 \mathrm{~h}$. Remarkably, the removal efficiency of the adsorbent remains at very high levels (above 99\%) even when the $C_{0}$ is increased by a factor of 4 (to $400 \mathrm{ppm}$ ). Hence, the lead uptake by the porous foam increases dramatically from $14.9 \mathrm{mg} / \mathrm{g}(100 \mathrm{ppm})$ to $52.9 \mathrm{mg} / \mathrm{g}(400 \mathrm{ppm})$, a fourfold increase. Further raising the $C_{0}$ level causes a decrease in the removal efficiency, dropping to values around $80-83 \%$ when the lead concentration ranges between 500 and 600 ppm, and dipping to $71.3 \%$ with $800 \mathrm{ppm}$. This decrease is explained by the change in the adsorbent's sorption kinetics induced by the modification of the $\mathrm{Pb}^{2+}$ initial concentration. This feature can be easily observed from the analysis of Fig. 6. As observed, an increase in the initial lead concentration delays the lead sorption by the foam. When $C_{0} \leq 400$ $\mathrm{ppm}$, the delay observed in the first $2 \mathrm{~h}$ is mostly negated after $4 \mathrm{~h}$. However, the use of higher concentrations $\left(C_{0} \geq 500 \mathrm{ppm}\right)$ further hinders the lead adsorption, as seen by the much lower removal 


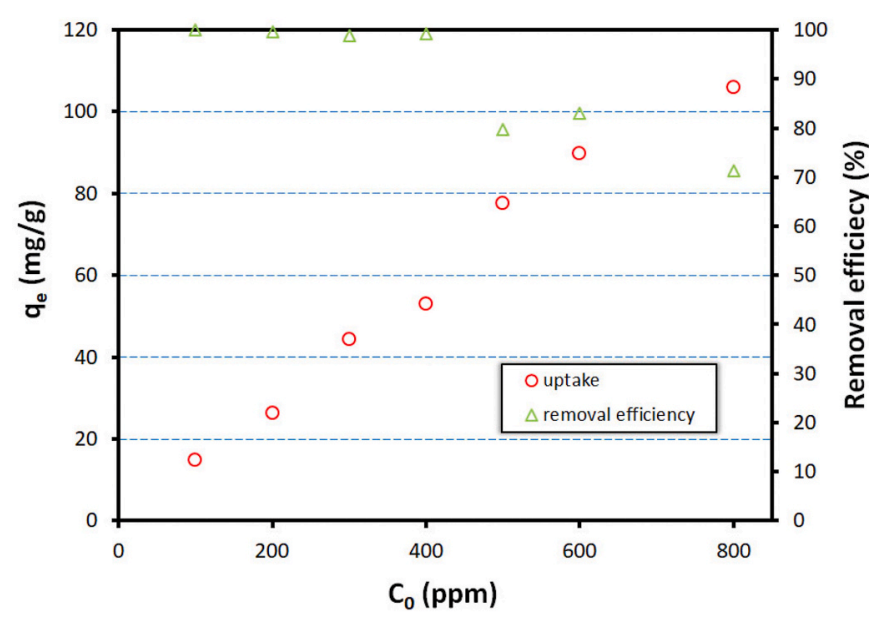

Fig. 5. Influence of lead initial concentration on the uptake and removal efficiency of this pollutant by the porous inorganic polymer foam $8 \boldsymbol{M}_{-} \mathbf{0 . 1 0 A l}(\mathrm{pH}$ $=5$, contact time: $4 \mathrm{~h}$, volume: $100 \mathrm{~mL}$ ).

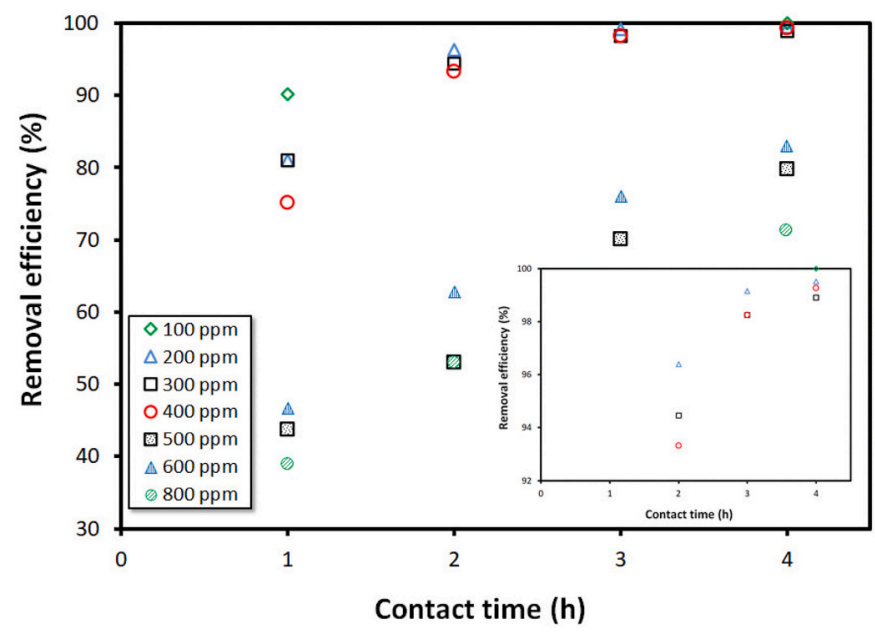

Fig. 6. Influence of the lead initial concentration on the removal efficiency kinetics for $8 \boldsymbol{M}_{-} \boldsymbol{0 . 1 0 A l}(\mathrm{pH}=5$, volume: $100 \mathrm{~mL}$ ). The inset better illustrate the specimens' lead removal efficiency when the pollutant concentration if below 400 ppm.

efficiency attained after $4 \mathrm{~h}$ (e.g. $71.3 \%-800 \mathrm{ppm}$ ). The adsorption trend shown when using concentrations above $500 \mathrm{ppm}$ suggests that the specimens do not reach their adsorption equilibrium within the maximum contact time considered here $(4 \mathrm{~h})$ at these lead levels, and therefore the use of higher adsorption times would most probably improve the removal efficiency levels. However, we have decided to keep this parameter constant, considering the results shown in section 3.2.1.

Our findings suggesting that sorption kinetics is pollutant concentration-dependent are in line with other literature studies performed with IPs (Novais et al., 2019b; Tang et al., 2018).

Despite the decrease in the lead removal efficiency when raising $C_{0}$ above $400 \mathrm{ppm}$, the adsorbent's lead removal capacity strongly increases (see Fig. 6), reaching an impressive $105.9 \mathrm{mg} / \mathrm{g}$ when $C_{0}=800$ ppm.

The lead adsorption by the porous foams was further evaluated by performing EDS maps on the specimens' surface and inner part (corresponding to their transversal section), results provided in Fig. 7. Fig. 7a shows that when $C_{0}=400 \mathrm{ppm}$, lead is uniformly distributed on the foams' surface but not in its inner part. Besides being heterogeneously distributed inside the sample, lead is also present in lower amounts, as depicted by comparing the EDS spectra given in Fig. 7a. However, much more lead diffuses into the specimens when increasing $C_{0}$ (Fig. $7 \mathrm{~b}$ and c), and this explains the abovementioned increase in the lead uptake from $52.9 \mathrm{mg} / \mathrm{g}$ (400 ppm) to $89.8 \mathrm{mg} / \mathrm{g}(600 \mathrm{ppm})$, and reaching $105.9 \mathrm{mg} / \mathrm{g}$ when $C_{0}=800 \mathrm{ppm}$. The EDS maps included in Fig. 7 also show that the lead distribution on the specimens is rather similar to that seen for silicon and aluminium, and this suggests that $\mathrm{Pb}^{2+}$ ions are acting as charge-balancing elements to the negatively charged aluminosilicate structure. The mechanism behind the $\mathrm{Pb}^{2+}$ stabilisation/fixation will be discussed in section 3.2.2.7.

The maximum lead adsorption capacity observed here was compared with that reported for all bulk-type (not powders) IP adsorbents reported to date, and results are shown in Fig. 8. In addition, our results were also compared in Fig. 8b with the most relevant studies addressing the use of powdered IP adsorbents, considering recent reviews on the topic (Luukkonen et al., 2019; Novais et al., 2020; Siyal et al., 2018). It should be highlighted that the IP microspheres reported in (Tang et al., 2018) were considered as "powders", despite the fact that their production differs from the conventional two-step route (involving casting the slurry and milling the cured sample), due to their small size ( $d=100$ $\mu \mathrm{m})$.

The lead uptake shown by these IP foams is the highest value reported to date for the use of bulk-type (not powders) IP adsorbents, being 2.3 times higher than the previous best performing bulk-type adsorbent - mm size spheres (Tang et al., 2015); 2.8 times higher than IP-supported zeolites (Khalid et al., 2018); 6.4 times higher than mm-size granules (Bumanis et al., 2019); and 16.8 times higher than those exhibited by cylindrical discs (Novais et al., 2016b). The outstanding performance of the foams is also demonstrated by the comparison with powdered adsorbents (see Fig. 8b). The lead adsorption by the porous foams surpasses several other studies considering powdered IPs, being 14 times higher than the value reported in (Panda et al., 2018); three times higher than in (López et al., 2014; Novais et al., 2016c); 1.3 times higher than in (Al-Zboon et al., 2011); and slightly superior to the study of Cheng et al. (100 mg/g) (Cheng et al., 2012). The uptake reported here is only slightly inferior to the value reported for fly ash IP particles (118.6 mg/g) (Liu et al., 2016), although it is nearly half of that seen for IP containing zeolites $(261.2 \mathrm{mg} / \mathrm{g}$ ) (Andrejkovičová et al., 2016), and much smaller than that of $100 \mu \mathrm{m}$ microspheres $(626.2$ $\mathrm{mg} / \mathrm{g}$ ) (Tang et al., 2018). However, in (Liu et al., 2016) a huge amount of zeolite ( $25 \mathrm{wt} \%$ ) was used in the adsorbent's synthesis. In addition, the value reported in Fig. 8b does not correspond to an experimental value but was predicted using a kinetic model (Langmuir). In fact, when using $\mathrm{C}_{0}=250 \mathrm{ppm}$ a much lower experimental value was seen for the lead uptake $(\sim 25 \mathrm{mg} / \mathrm{g})$. The value observed when using IP microspheres is remarkable (626.2 mg/g) (Tang et al., 2018). Nevertheless, the adsorbent synthesis is complex, involving a long heat treatment $(6 \mathrm{~h}$ at $450{ }^{\circ} \mathrm{C}$ ), and the small size of the particles (below $100 \mu \mathrm{m}$ ) not only hinders their direct use in packed beds, but would most probably require the use of a separation step after adsorption. On the contrary, our specimens, produced using a simple synthesis protocol involving curing at room temperature, can be installed directly in packed beds and easily retrieved after exhaustion without the need of expensive post-separation steps (e.g. ultrafiltration). These are very promising results suggesting that bulk-type adsorbents could be a very powerful and safer alternative to the use of powdered adsorbents in wastewater depollution systems.

3.2.2.3. Influence of $\mathrm{pH}$. Fig. $\mathrm{S} 6$ presents the effect of $\mathrm{pH}$ on the uptake and the removal efficiency of this metal ion by the IP foams in the range between 2 and 5 . The amount of lead adsorbed strongly increases within the studied $\mathrm{pH}$ range, the uptake increasing from $\sim 6$ to $\sim 53 \mathrm{mg} / \mathrm{g}$. The removal efficiency follows the same increasing trend, going from a modest $7.6 \%$ in the lower $\mathrm{pH}$ range $(\mathrm{pH}=2)$, to reach an impressive $100 \%$ at the highest $\mathrm{pH}$. This behaviour is associated with the higher availability of $\mathrm{H}^{+}$ions at lower $\mathrm{pH}$, competing with the lead ions for the 

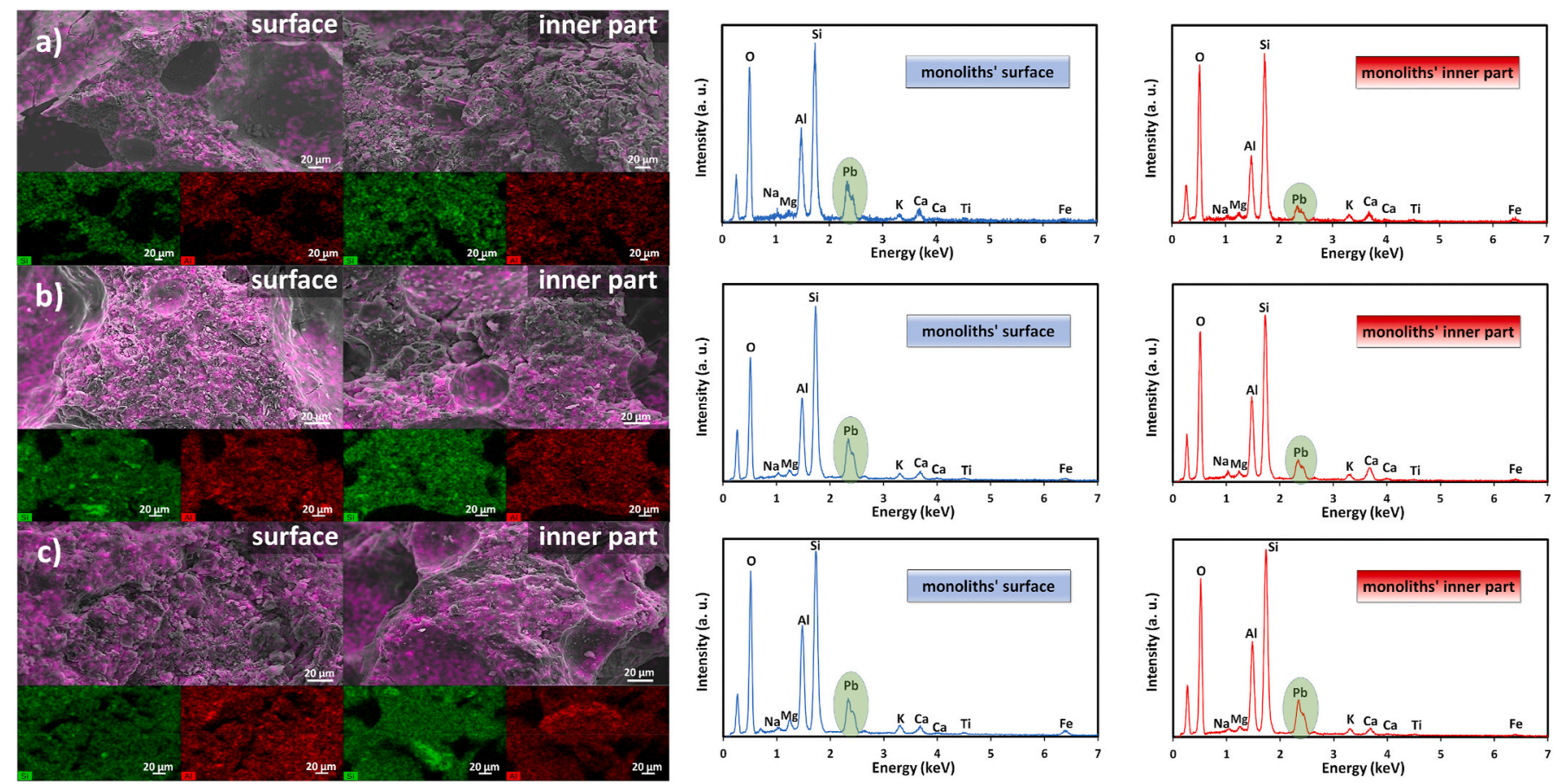

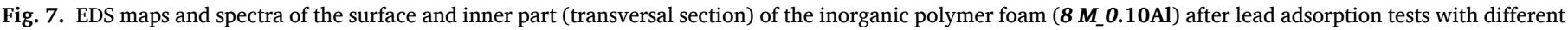
initial lead concentrations: a) $400 \mathrm{ppm}$, b) $600 \mathrm{ppm}$ and c) $800 \mathrm{ppm}$ (pH = 5, contact time: 4 h, volume: $100 \mathrm{~mL}$ ).

a)

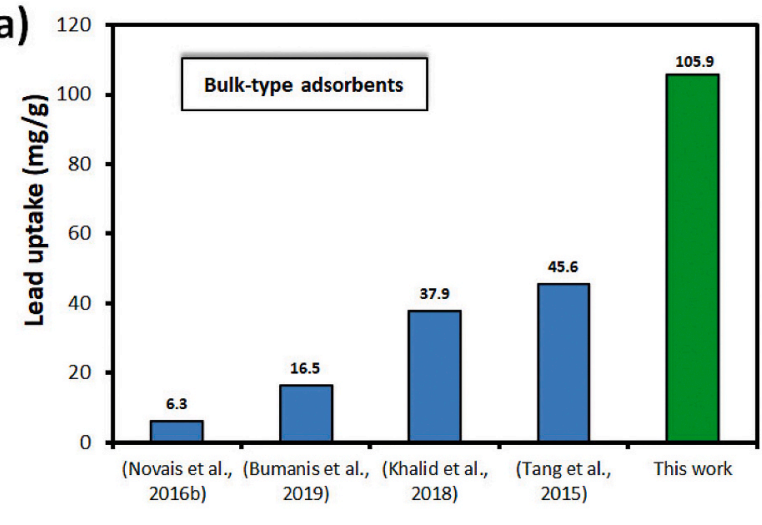

b)

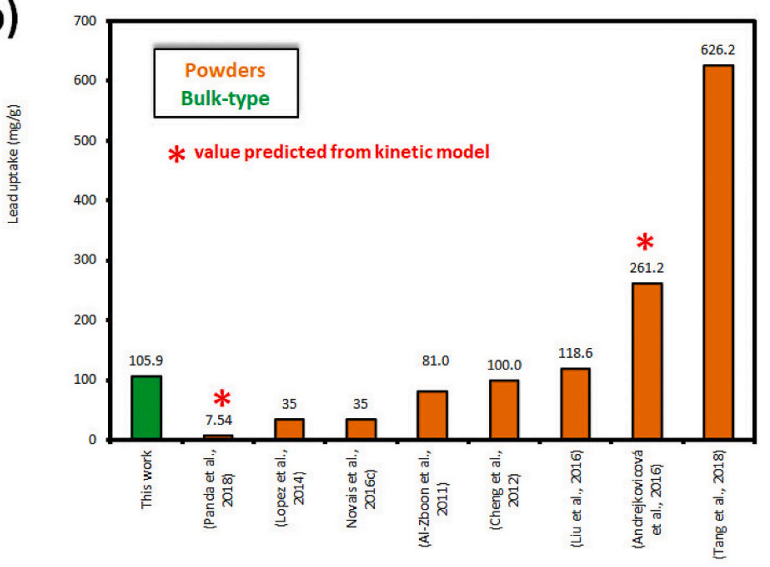

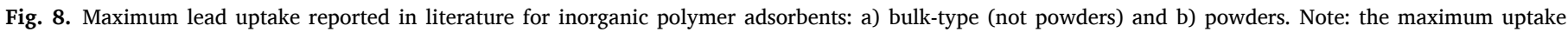

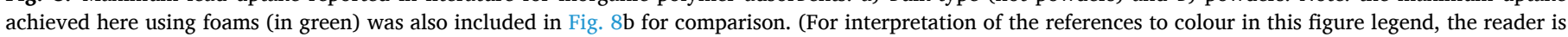
referred to the Web version of this article.)

binding sites on the adsorbent, and this hinders the $\mathrm{Pb}^{2+}$ extraction. As the $\mathrm{pH}$ rises, the abundance of $\mathrm{H}^{+}$ions decreases, and as a result a higher number of active sites are available for the $\mathrm{Pb}^{2+}$ ions favouring its uptake. Our results are in line with previous studies performed using powdered IPs (Al-Zboon et al., 2011; Cheng et al., 2012).

3.2.2.4. Influence of the ionic strength. In wastewaters, the presence of salts (e.g. $\mathrm{NaCl}$ ) coexisting with the metal ion is to be expected, and their presence might affect the $\mathrm{Pb}^{2+}$ extraction due to the competition between the cations for the binding sites. Fig. S7a shows that the adsorption kinetics is affected by the presence of $\mathrm{Na}^{+}$, a much lower sorption being observed when sodium ions are present. Nevertheless, the differences between the removal efficiencies tend to decrease with sorption time suggesting that longer sorption times might be required in real wastewaters to reach the adsorbents' full potential. The lead uptake by the foams under various ionic strengths, shown in Fig. S7b, increases steadily with sorption time in all compositions, but at a much higher pace in the $\mathrm{Na}^{+}$containing solutions. After $4 \mathrm{~h}$ sorption, the uptake seen for the higher ionic strength solution $(0.1 \mathrm{mM} \mathrm{NaCl})$ is $48.2 \mathrm{mg} / \mathrm{g}$, this being $\sim 9 \%$ lower than the value reached in the lower ionic strength solution $(0 \mathrm{mM} \mathrm{NaCl} ; 52.9 \mathrm{mg} / \mathrm{g})$. These results are in good agreement with the modification of the adsorbent surface charge properties discussed above.

3.2.2.5. Influence of $\mathrm{Pb}^{2+}$ solution volume. To evaluate the influence of the adsorbent-to-adsorbate ratio on the lead uptake and removal efficiency by the porous IP foams when using high lead concentrations (400 $\mathrm{ppm}$ ), the volume of the lead solution was varied between 100 and 250 $\mathrm{mL}$, and the results are illustrated in Fig. 9. By increasing the solution volume from 100 to $200 \mathrm{~mL}$, the lead uptake of the foam increases substantially, from 52.9 to $85.0 \mathrm{mg} / \mathrm{g}$, while the opposite trend is seen for the removal efficiency, which declines from 99.3 to $81.9 \%$. When the 

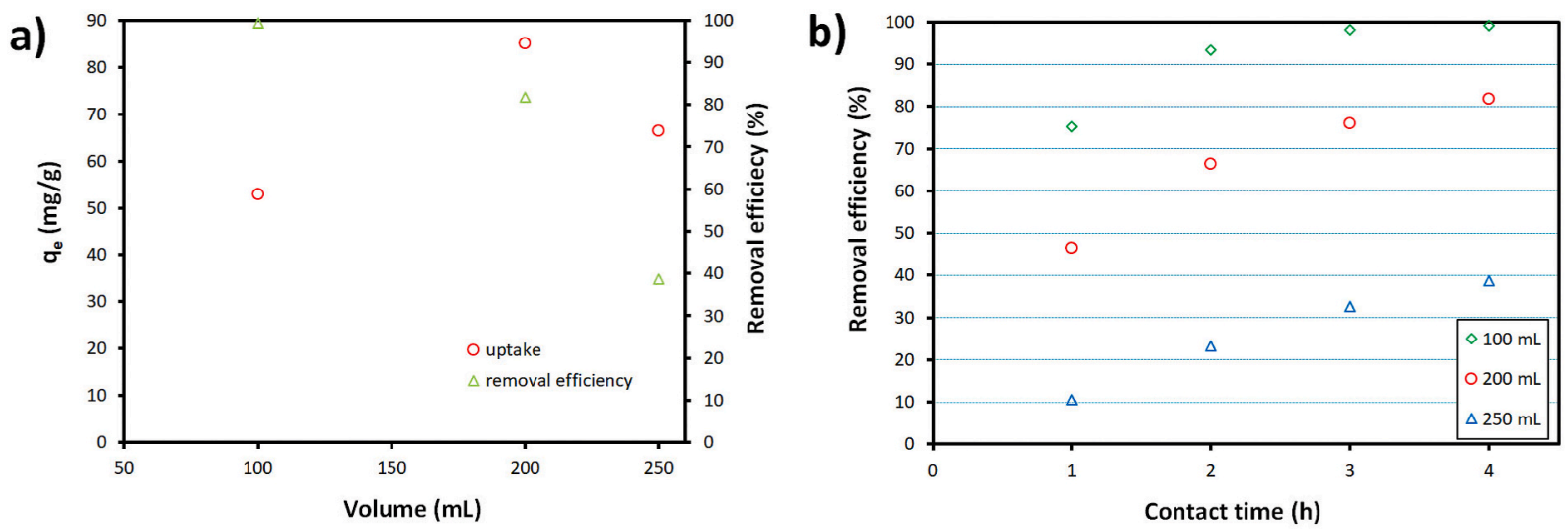

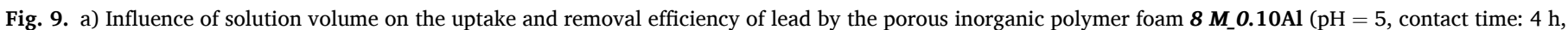
$\left.\left[\mathrm{Pb}^{2+}\right]: 400 \mathrm{ppm}\right)$. Fig. 9b illustrates the influence of the solution volume on the sorption kinetics $\left(\mathrm{pH}=5,\left[\mathrm{~Pb}^{2+}\right]: 400 \mathrm{ppm}\right)$.

solution volume increases (i.e. lower adsorbent-to-adsorbate ratio) the number of adsorption sites drops due to the lower availability of adsorbent surface per volume, thus explaining the decrease in the removal efficiency. Fig. $9 \mathrm{~b}$ shows a strong decline in the adsorption rate when raising the solution volume. However, the differences in the removal efficiency $(\Delta \mathrm{E})$ decrease as the sorption time rises. After the 1st hour, the removal efficiency is $75.1 \%$ with $100 \mathrm{~mL}$, this being roughly $29 \%$ higher than that seen with $200 \mathrm{~mL}$ (46.6\%). After the 3rd hour $\Delta \mathrm{E}$ slightly decreases to $22 \%$, further decreasing to $17 \%$ after $4 \mathrm{~h}$.

Results also show that if the volume further increases to $250 \mathrm{~mL}$ the removal efficiency drops significantly and, therefore, the lead uptake also decreases. The trend seen in Fig. 9b indicates that under these conditions the foams do not reach their equilibrium, i.e. no percolation is seen, which might explain the drop in their performance. In any case, longer contact times would most probably enhance the adsorbent's potential under these lower adsorbent-to-adsorbate ratios.

Based on these results, considering a $4 \mathrm{~h}$ sorption time, two scenarios can be envisaged: i) the most efficient solution - the $100 \mathrm{~mL}$ promotes the highest lead removal efficiency ( $>99 \%$ ); and ii) the most costeffective solution - the use of $200 \mathrm{~mL}$ decreases the adsorbent amount by half, but still ensures an interesting adsorption capacity $(81.9 \%-4 \mathrm{~h})$ at a very high lead initial concentration (400 ppm).

3.2.2.6. Regeneration of the foams. The lead desorption from the foams was studied using mild acidic conditions $\left(\mathrm{HNO}_{3}, 0.01 \mathrm{M}\right)$ on samples obtained from the adsorption tests, namely those exhibiting the highest lead uptake $\left(89.8 \mathrm{mg} / \mathrm{g}\left(\mathrm{C}_{0}=600\right)\right.$ and $\left.105.9 \mathrm{mg} / \mathrm{g}\left(\mathrm{C}_{0}=800 \mathrm{ppm}\right)\right)$. The lead desorption ratio was calculated using equation Eq. (A3) as reported in (Novais et al., 2016b). After $60 \mathrm{~min}$, a very high desorption ratio was seen in the highest lead-containing samples (coded as R1) reaching $66.8 \%$, while their lower lead-containing counterparts (coded as R2) leached a lower amount (52.7\%). Therefore, the leaching period in the latter samples was extended. After $2 \mathrm{~h}$ immersion in $\mathrm{HNO}_{3}$, the desorption ratio in $\mathrm{R} 2$ further increased to $67.1 \%$. These results show that lead can be rapidly extracted from the foams by using mild acidic conditions, but also that the leaching efficiency is dependent on the amount of lead present in the specimens, higher amounts leaching faster. The desorption ratio here observed is $\sim 12 \%$ lower than that seen for IP spheres (79\%) (Tang et al., 2018), but using harsher desorption conditions $\left(0.1 \mathrm{M} \mathrm{HNO}_{3} ; 12 \mathrm{~h}\right)$. In fact, the authors stated that these conditions induced structural damage in the adsorbents, and for that reason they were avoided here. Future work will investigate the feasibility of using longer leaching periods to further enhance the lead recovery rate.

The regenerated samples were them reused as adsorbent, and results are presented in Fig. S8. The specimens showed similar adsorption behaviour, even if slightly higher removal efficiencies and uptake were reached by $\mathrm{R} 2$ ( $93.5 \%$ and $19.8 \mathrm{mg} / \mathrm{g}$ ) in comparison with $\mathrm{R} 1$ ( $85 \%$ and $18.6 \mathrm{mg} / \mathrm{g}$ ). Despite showing similar desorption ratios, the amount of lead remaining in the specimens' structure after the desorption differs, being roughly $35 \mathrm{mg} / \mathrm{g}$ in $\mathrm{R} 1$ and $30 \mathrm{mg} / \mathrm{g}$ in $\mathrm{R} 2$. This means that the number of active sites available for lead adsorption is somewhat higher in R2, thus explaining the slightly different adsorption. Impressively, the uptake shown by the regenerated samples is superior to that seen in the 1st adsorption cycle ( $14.9 \mathrm{mg} / \mathrm{g}$; see Fig. 5) and this demonstrates that the IP foams can be successfully regenerated and reused as lead adsorbents.

3.2.2.7. Adsorption mechanism. Previous reports have suggested two possible mechanisms for $\mathrm{Pb}^{2+}$ stabilisation/fixation in IPs: i) coordination of lead with nonbridging $\mathrm{Si}_{-} \mathrm{O}^{-}$and $\mathrm{Al}-\mathrm{O}^{-}$belonging to the IP framework (chemical bonding) (El-eswed et al., 2017); and/or ii) by ion-exchange between lead ions and the sodium cations present in the IP framework (Luukkonen et al., 2019; Yan et al., 2019).

To better understand the lead adsorption mechanism of these foams, FTIR spectra before and after lead adsorption were collected for $\boldsymbol{8}$ M_0.10Al, and results are given in Fig. S9. The spectrum before lead adsorption shows the characteristic peaks seen in IPs: a broad asymmetric band at $3200-3400 \mathrm{~cm}^{-1}$ corresponding to adsorbed $\mathrm{H}_{2} \mathrm{O}$, while the bending vibration of water is responsible for the peak seen at 1633 $\mathrm{cm}^{-1}$ (Sarkar et al., 2017). The high intensity fingerprint band of IPs (Rees et al., 2007) located at $1034 \mathrm{~cm}^{-1}$ is assigned to the asymmetric stretching of Si-O-Si/Al-O-Al (Liew et al., 2016), while the peak at 778 $\mathrm{cm}^{-1}$ belongs to the symmetric stretching of T-O bonds ( $\mathrm{T}=\mathrm{Al}, \mathrm{Si}$ ) (Liew et al., 2016). After lead adsorption, the most relevant feature is the blueshift of the Si-O-Si/Al-O-Al stretching band to $994 \mathrm{~cm}^{-1}$. A shift in this band has been associated with the presence of heavy metals. This has been frequently observed for heavy metal-containing IPs in which the heavy metals were added during synthesis in very high amounts (up to 3 wt\%) (Huang et al., 2016; Rees et al., 2007), although barely addressed in studies dealing with heavy metals adsorption by IPs. One of the exceptions to this is the work of Kara et al., which observed a redshift after $\mathrm{Ni}$ and $\mathrm{Zn}$ adsorption, but did not provide any explanation for this feature (Kara et al., 2017). Similar to our result, Huang et al. observed a blueshift in the $\mathrm{Si}-\mathrm{O}-\mathrm{Si} / \mathrm{Al}-\mathrm{O}-\mathrm{Al}$ stretching band in a chromite-containing IP in comparison with their reference composition (without heavy metals) (Huang et al., 2016). These authors suggested that this behaviour is a consequence of the replacement of sodium and calcium ions by chromium, which would consequently equilibrate the negative charge of the IP. Similar behaviour and explanation was given in Refs (Rees et al., 2007) and (Muhammad et al., 2018) studying the stabilisation of various heavy metals (including lead) in IPs. Lee et al. also observed a shift in the band associated with the $\mathrm{Si}-\mathrm{O}-\mathrm{T}$ band in lead-doped specimens; however, they found no specific trend when 
increasing the lead amount (Lee et al., 2016). These authors have observed with EDS elemental mapping that the lead distribution in the specimen was not associated with the silicon distribution, suggesting that lead has not formed a chemical compound with silicon in their material. On the contrary, we have seen (see Fig. 7) that the lead distribution within the specimen mimics that observed for both silicon and aluminium, which indicates that there is a strong interaction between lead and the aluminosilicate framework. The exact mechanism for lead adsorption by IPs is not yet totally understood to date, and the possibility of multiple contributing mechanisms cannot be ruled out (e.g. chemical interaction between the heavy metal ions and the functional groups present in the IP surface (Lan et al., 2019); ion exchange and physical encapsulation (Ji and Pei, 2019; Li et al., 2018)). Nevertheless, the very high leaching levels ( $\sim 67 \%$ ) obtained during the desorption tests provide strong evidence that the prevailing mechanism behind $\mathrm{Pb}^{2+}$ adsorption by the foams is ion exchange.

3.2.2.8. Adsorption isotherm model studies. The lead adsorption by the IP foams was studied using the Freundlich (1906) and Langmuir (1918) isotherm models by fitting the experimental results using Eq. (A4) and Eq. (A5), respectively. These models have been widely used to characterise the pollutants' adsorption and the adsorbate/adsorbent interaction when using IP adsorbents (Al-Zboon et al., 2011; Tang et al., 2018). Fig. 10 shows the fitting of the experimental values using the Freundlich and the Langmuir models, while Table 2 lists the adsorption parameters calculated for each of the models. The isotherms presented in Fig. 10 show that both models fit well with our results. Nevertheless, a higher accuracy is reached with the Langmuir model $\left(\mathrm{R}^{2}=0.966\right)$ suggesting that the $\mathrm{Pb}^{2+}$ sorption mechanism takes place via monolayer adsorption on the foams. Moreover, the separation factor $\left(R_{\mathrm{L}}\right.$; see Eq. (A6)) is always greater than zero, ranging from 0.0027 to 0.0216 depending on the $\mathrm{C}_{0}$, implying that adsorption is favourable at least in the concentration range considered here $(100-800 \mathrm{ppm})$. It was also observed that $R_{\mathrm{L}}$ decreases when the initial lead concentration rises (see Fig. 10c), and this indicates that adsorption is favoured at higher concentrations (Vargas et al., 2011). In fact, this is in line with the results discussed in section 3.2.2.2 (see Figs. 5 and 7) which showed much higher lead uptake when $\mathrm{C}_{0}$ rises from 100 to $800 \mathrm{ppm}$. Our results are in line with other literature studies in which a better fitting of the experimental results was also seen with the Langmuir model (Al-Zboon et al., 2011; Tang et al., 2018). The theoretical maximum adsorption capacity calculated from the Langmuir isotherm $(87.72 \mathrm{mg} / \mathrm{g})$ is reasonably close, but slightly inferior to, the maximum experimental value $(105.9 \mathrm{mg} / \mathrm{g})$, which again suggests that it can be used to describe the interaction between the adsorbate and the adsorbent.

Despite having lower accuracy, the Freundlich model also indicates that lead adsorption by the foams is a favourable process, since the Freundlich adsorption parameter $n$ (4.80) is between 1 and 10 , similar to previous studies (Al-Zboon et al., 2011; Novais et al., 2019b).

\section{Conclusions}

Herein, highly porous IP foams were synthesised using a simple, environmentally friendly, and low-cost protocol using an industrial waste as the main solid precursor. The foams were then used as bulktype adsorbents to extract lead from aqueous solutions, differing from the conventional route employing powdered IPs whose recovery after use is complex. Results showed that low $\mathrm{pHs}$ and the presence of competing ions (e.g. $\mathrm{Na}^{+}$) are detrimental to $\mathrm{Pb}^{2+}$ adsorption. At $\mathrm{pH} 5$, the foams exhibited very high affinity for $\mathrm{Pb}^{2+}$ ions as demonstrated by the fast equilibrium time $(4 \mathrm{~h})$ and the impressive lead removal capacity (105.9 $\mathrm{mg} / \mathrm{g}, 0 \mathrm{mM} \mathrm{NaCl}$ ). The maximum lead uptake is the highest value ever reported for $\mathrm{cm}$-size IPs, being several times superior to previous studies on this topic and more than doubling the value reported in the previous best performing IP (e.g. mm-size spheres). Remarkably,
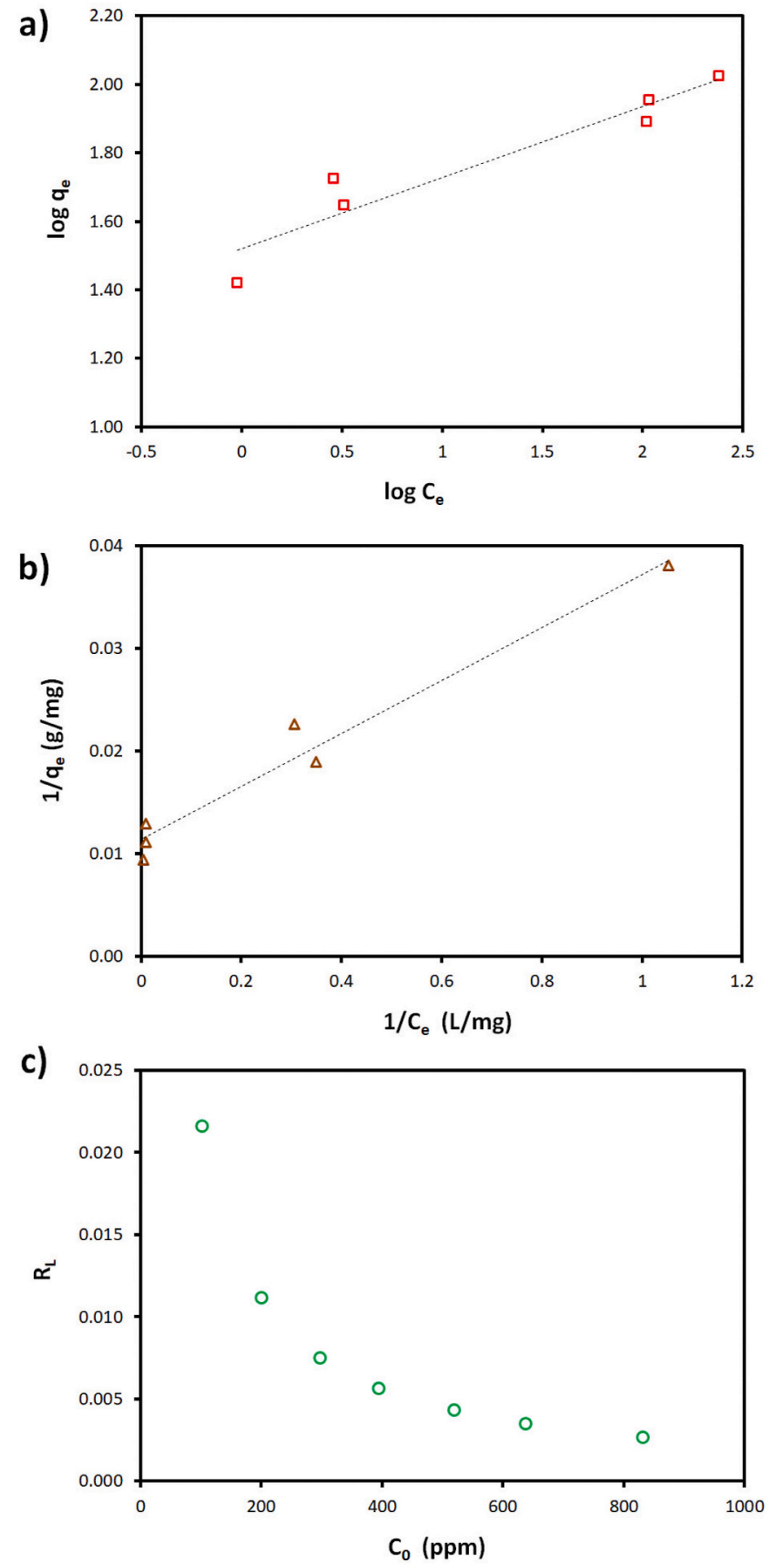

Fig. 10. Adsorption isotherms using a) Freundlich and b) Langmuir models (contact time: $4 \mathrm{~h}$, volume: $100 \mathrm{~mL}$ ). c) Langmuir separation factor.

Table 2

Adsorption parameters calculated for the lead adsorption by the porous inorganic polymer $\mathbf{8} \boldsymbol{M}_{-} \mathbf{0 . 1 0 A l}$ by fitting the experimental data using the Freundlich and the Langmuir models ( $\mathrm{pH}=5$, contact time: $4 \mathrm{~h}$, volume: $100 \mathrm{~mL}$ ).

\begin{tabular}{|c|c|c|c|c|c|c|}
\hline \multirow[t]{2}{*}{ Sample } & \multicolumn{3}{|l|}{ Freundlich } & \multicolumn{3}{|c|}{ Langmuir } \\
\hline & $\begin{array}{l}\mathrm{K}_{\mathrm{F}}(\mathrm{mg} / \mathrm{g}) \\
(\mathrm{L} / \mathrm{g})^{\mathrm{n}}\end{array}$ & $\mathrm{n}$ & $\mathrm{R}^{2}$ & $\begin{array}{l}\mathrm{q}_{\max } \\
(\mathrm{mg} / \mathrm{g})\end{array}$ & $\begin{array}{l}\mathrm{K}_{\mathrm{L}}(\mathrm{L} / \\
\mathrm{mg})\end{array}$ & $\mathrm{R}^{2}$ \\
\hline $\begin{array}{c}8 \mathrm{M} \mathrm{M}_{-} 0.05 \mathrm{wt} \\
\% \mathrm{Al}\end{array}$ & 33.12 & 4.80 & 0.905 & 87.72 & 0.44 & 0.966 \\
\hline
\end{tabular}


their lead uptake is amongst the highest reported to date regardless of the IPs' size ( $\mu \mathrm{m}$ or $\mathrm{mm})$, surpassing several studies focusing the use of powdered IPs, and this shows that the use of proper mixing protocol (e.g. foaming agent amount and activator molarity) enables the production of foams possessing high specific surface area $\left(\sim 42 \mathrm{~m}^{2} / \mathrm{g}\right)$ and tailored porosity, and with excellent lead adsorption capacity. The foams can be easily regenerated and reused as lead adsorbent, further demonstrating their interesting potential.

\section{Declaration of competing interest}

The authors declare that they have no known competing financial interests or personal relationships that could have appeared to influence the work reported in this paper.

\section{CRediT authorship contribution statement}

Rui M. Novais: Conceptualization, Methodology, Validation, Writing - original draft, Writing - review \& editing, Supervision. João Carvalheiras: Investigation, Validation, Writing - review \& editing. Maria P. Seabra: Writing - review \& editing. Robert C. Pullar: Writing review \& editing. João A. Labrincha: Writing - review \& editing, Supervision.

\section{Acknowledgements}

Novais (CEECIND/00335/2017), Carvalheiras (SFRH/BD/144562/ 2019) and Pullar (IF/00681/2015) wish to thank FCT for supporting their work. This work was developed within the scope of the project CICECO-Aveiro Institute of Materials, UIDB/50011/2020 \& UIDP/ $50011 / 2020$, financed by national funds through the Foundation for Science and Technology/MCTES.

\section{Appendix A. Supplementary data}

Supplementary data to this article can be found online at https://doi. org/10.1016/j.jenvman.2020.111049.

\section{References}

Al-Zboon, K., Al-Harahsheh, M.S., Hani, F.B., 2011. Fly ash-based geopolymer for $\mathrm{Pb}$ removal from aqueous solution. J. Hazard Mater. 188, 414-421. https://doi.org/ 10.1016/j.jhazmat.2011.01.133.

Alharbi, N.S., Hu, B., Hayat, T., Rabah, S.O., Alsaedi, A., Zhuang, L., Wang, X., 2020. Efficient elimination of environmental pollutants through sorption-reduction and photocatalytic degradation using nanomaterials. Front. Chem. Sci. Eng. https://doi. org/10.1007/s11705-020-1923-z.

Alwan, G.M., 2008. pH control problems of a wastewater treatment plant. Al-Khwarizmi Eng. J. 4, 37-45.

Alwan, G., 2012. Adaptive genetic pH control of a wastewater treatment unit via LAB view. J. Chem. Process Eng. Res. 5, 22-32.

Andrejkovičová, S., Sudagar, A., Rocha, J., Patinha, C., Hajjaji, W., Da Silva, E.F., Velosa, A., Rocha, F., 2016. The effect of natural zeolite on microstructure, mechanical and heavy metals adsorption properties of metakaolin based geopolymers. Appl. Clay Sci. 126, 141-152. https://doi.org/10.1016/j. clay.2016.03.009.

Bai, C., Colombo, P., 2018. Processing, properties and applications of highly porous geopolymers: a review. Ceram. Int. 44, 16103-16118. https://doi.org/10.1016/j. ceramint.2018.05.219.

Bumanis, G., Novais, R.M., Carvalheiras, J., Bajare, D., Labrincha, J.A., 2019. Metals removal from aqueous solutions by tailored porous waste-based granulated alkaliactivated materials. Appl. Clay Sci. 179, 105147. https://doi.org/10.1016/j. clay.2019.105147.

Cheng, T.W., Lee, M.L., Ko, M.S., Ueng, T.H., Yang, S.F., 2012. The heavy metal adsorption characteristics on metakaolin-based geopolymer. Appl. Clay Sci. 56, 90-96. https://doi.org/10.1016/j.clay.2011.11.027.

El-eswed, B.I., Aldagag, O.M., Khalili, F.I., 2017. Efficiency and mechanism of stabilization/solidification of $\mathrm{Pb}$ (II), Cd (II), Cu (II), Th (IV) and U (VI) in metakaolin based geopolymers. Appl. Clay Sci. 140, 148-156. https://doi.org/ 10.1016/j.clay.2017.02.003.

Freundlich, H.M.F., 1906. Uber die adsorption in losungen. Zeitschrift fur Phys. Chemie 57, 385-470.

Fu, F., Wang, Q., 2011. Removal of heavy metal ions from wastewaters : a review. J. Environ. Manag. 92, 407-418. https://doi.org/10.1016/j.jenvman.2010.11.011.
Ge, Y., Yuan, Y., Wang, K., He, Y., Cui, X., 2015. Preparation of geopolymer-based inorganic membrane for removing Ni2+from wastewater. J. Hazard Mater. 299, 711-718. https://doi.org/10.1016/j.jhazmat.2015.08.006.

Gopinath, K.P., Madhav, N.V., Krishnan, A., Malolan, R., Rangarajan, G., 2020. Present applications of titanium dioxide for the photocatalytic removal of pollutants from water: a review. J. Environ. Manag. 270, 110906. https://doi.org/10.1016/j. jenvman.2020.110906.

Hu, B., Ai, Y., Jin, J., Hayat, T., Alsaedi, A., Zhuang, L., Wang, X., 2020. Efficient elimination of organic and inorganic pollutants by biochar and biochar-based materials. Biochar 2, 47-64. https://doi.org/10.1007/s42773-020-00044-4.

Huang, X., Huang, T., Li, S., Muhammad, F., Xu, G., Zhao, Z., Yu, L., Yan, Y., Li, D., Jiao, B., 2016. Immobilization of chromite ore processing residue with alkaliactivated blast furnace slag-based geopolymer. Ceram. Int. 42, 9538-9549. https:// doi.org/10.1016/j.ceramint.2016.03.033.

Ji, Z., Pei, Y., 2019. Bibliographic and visualized analysis of geopolymer research and its application in heavy metal immobilization: a review. J. Environ. Manag. 231, 256-267. https://doi.org/10.1016/j.jenvman.2018.10.041.

Kara, İ., Yilmazer, D., Akar, S.T., 2017. Metakaolin based geopolymer as an effective adsorbent for adsorption of zinc(II) and nickel(II) ions from aqueous solutions. Appl. Clay Sci. 139, 54-63. https://doi.org/10.1016/j.clay.2017.01.008.

Khalid, H.R., Lee, N.K., Park, S.M., Abbas, N., Lee, H.K., 2018. Synthesis of geopolymersupported zeolites via robust one-step method and their adsorption potential. J. Hazard Mater. 353, 522-533. https://doi.org/10.1016/j.jhazmat.2018.04.049.

Kriven, W.M., Bell, J.L., Gordon, M., 2003. Microstructure and microchemistry of fullyreacted geopolymers and geopolymer matrix composites. Ceram. Trans. 153, $227-250$.

Lan, T., Li, P., Rehman, F.U., Li, X., Yang, W., Guo, S., 2019. Efficient adsorption of $\mathrm{Cd}^{2+}$ from aqueous solution using metakaolin geopolymers. Environ. Sci. Pollut. Res. 33555-33567.

Langmuir, I., 1918. The adsorption of gases on plane surfaces of glass, mica and platinum. J. Am. Ceram. Soc 40 (9), 1361-1403.

Lee, S., Riessen, A. Van, Chon, C., Kang, N., Jou, H., Kim, Y., 2016. Impact of activator type on the immobilisation of lead in fly ash-based geopolymer. J. Hazard Mater. 305, 59-66.

Li, S., Huang, X., Muhammad, F., Yu, L., Xia, M., Zhao, J., 2018. Waste solidification/ stabilization of lead-zinc slag by utilizing fly ash based geopolymers. RSC Adv. 32956-32965. https://doi.org/10.1039/c8ra06634e.

Liew, Y.M., Heah, C.Y., Mohd Mustafa, A.B., Kamarudin, H., 2016. Structure and properties of clay-based geopolymer cements: a review. Prog. Mater. Sci. 83, 595-629. https://doi.org/10.1016/j.pmatsci.2016.08.002.

Liu, Y., Yan, C., Zhang, Z., Wang, H., Zhou, S., Zhou, W., 2016. A comparative study on fly ash, geopolymer and faujasite block for $\mathrm{Pb}$ removal from aqueous solution. Fuel 185, 181-189. https://doi.org/10.1016/j.fuel.2016.07.116.

López, F.J., Sugita, S., Tagaya, M., Kobayashi, T., 2014. Metakaolin-based geopolymers for targeted adsorbents to heavy metal ion separation. J. Mater. Sci. Chem. Eng. 2, 16-27. https://doi.org/10.4236/msce.2014.27002.

Luukkonen, T., Heponiemi, A., Runtti, H., Pesonen, J., Yliniemi, J., Lassi, U., 2019. Application of alkali-activated materials for water and wastewater treatment: a review. Rev. Environ. Sci. Bio/Technology. https://doi.org/10.1007/s11157-01909494-0.

Mekonnen, M.M., Hoekstra, A.Y., 2016. Sustainability: four billion people facing severe water scarcity. Sci. Adv. 2, 1-7. https://doi.org/10.1126/sciadv.1500323.

Muhammad, F., Huang, X., Li, S., Xia, M., Zhang, M., Liu, Q., 2018. Strength evaluation by using polycarboxylate superplasticizer and solidification efficiency of $\mathrm{Cr}^{6+}, \mathrm{Pb}^{2+}$ and $\mathrm{Cd}^{2+}$ in composite based geopolymer. J. Clean. Prod. 188, 807-815. https://doi. org/10.1016/j.jclepro.2018.04.033.

Novais, R.M., Buruberri, L.H., Ascensão, G., Seabra, M.P., Labrincha, J.A., 2016a. Porous biomass fly ash-based geopolymers with tailored thermal conductivity. J. Clean. Prod. 119, 99-107. https://doi.org/10.1016/j.jclepro.2016.01.083.

Novais, R.M., Buruberri, L.H., Seabra, M.P., Labrincha, J.A., 2016b. Novel porous fly-ash containing geopolymer monoliths for lead adsorption from wastewaters. J. Hazard Mater. 318, 631-640. https://doi.org/10.1016/j.jhazmat.2016.07.059.

Novais, R.M., Ribeiro, A., Seabra, P., Tarelho, L., 2016c. Novel biomass fly ash-based geopolymers for environmental applications. Int. J. Renew. Energy Sources 1, 20-25.

Novais, R.M., Carvalheiras, J., Senff, L., Seabra, M.P., Pullar, R.C., Labrincha, J.A., 2019a. In-depth investigation of the long-term strength and leaching behaviour of inorganic polymer mortars containing green liquor dregs. J. Clean. Prod. 220, 630-641. https://doi.org/10.1016/j.jclepro.2019.02.170.

Novais, R.M., Carvalheiras, J., Tobaldi, D.M., Seabra, M.P., Pullar, R.C., Labrincha, J.A., 2019b. Synthesis of porous biomass fly ash-based geopolymer spheres for efficient removal of methylene blue from wastewaters. J. Clean. Prod. 207, 350-362. https:// doi.org/10.1016/j.jclepro.2018.09.265.

Novais, R.M., Pullar, R.C., Labrincha, J.A., 2020. Geopolymer foams: an overview of recent advancements. Prog. Mater. Sci. 109, 100621. https://doi.org/10.1016/j. pmatsci.2019.100621.

Panda, L., Rath, S.S., Srinivas, D., Nayak, B.B., Das, B., Misra, P.K., 2018. Thorough understanding of the kinetics and mechanism of heavy metal adsorption onto a pyrophyllite mine waste based geopolymer. J. Mol. Liq. 263, 428-441. https://doi. org/10.1016/j.molliq.2018.05.016.

Pang, H., Wu, Y., Wang, Xiangxue, Hu, B., Wang, Xiangke, 2019. Recent advances in composites of graphene and layered double hydroxides for water remediation: a review. Chem. Asian J. 14, 2542-2552. https://doi.org/10.1002/asia.201900493.

Rees, C.A., Provis, J.L., Lukey, G.C., Deventer, J.S.J., Van, 2007. In situ ATR-FTIR study of the early stages of fly ash geopolymer gel formation. Langmuir 9076-9082. https://doi.org/10.1021/la701185g. 
Sarkar, C., Basu, J.K., Samanta, A.N., 2017. Removal of Ni2+ ion from waste water by Geopolymeric Adsorbent derived from LD Slag. J. Water Process Eng. 17, 237-244. https://doi.org/10.1016/j.jwpe.2017.04.012.

Siyal, A.A., Shamsuddin, M.R., Khan, M.I., Rabat, N.E., Zulfiqar, M., Man, Z., Siame, J., Azizli, K.A., 2018. A review on geopolymers as emerging materials for the adsorption of heavy metals and dyes. J. Environ. Manag. 224, 327-339. https://doi.org/ 10.1016/j.jenvman.2018.07.046.

Tang, Q., Ge, Y. yuan, Wang, K. tuo, He, Y., Cui, X. min, 2015. Preparation and characterization of porous metakaolin-based inorganic polymer spheres as an adsorbent. Mater. Des. 88, 1244-1249. https://doi.org/10.1016/j. matdes.2015.09.126.
Tang, Q., Wang, K., Yaseen, M., Tong, Z., Cui, X., 2018. Synthesis of highly efficient porous inorganic polymer microspheres for the adsorptive removal of $\mathrm{Pb}^{2+}$ from wastewater. J. Clean. Prod. 193, 351-362. https://doi.org/10.1016/j. jclepro.2018.05.094.

Vargas, A.M.M., Cazetta, A.L., Kunita, M.H., Silva, T.L., Almeida, V.C., 2011. Adsorption of methylene blue on activated carbon produced from flamboyant pods (Delonix regia ): study of adsorption isotherms and kinetic models. Chem. Eng. J. 168, 722-730. https://doi.org/10.1016/j.cej.2011.01.067.

Yan, S., Zhang, F., Wang, L., Rong, Y., He, P., Jia, D., Yang, J., 2019. A green and lowcost hollow gangue microsphere/geopolymer adsorbent for the effective removal of heavy metals from wastewaters. J. Environ. Manag. 246, 174-183. https://doi.org/ 10.1016/j.jenvman.2019.05.120. 